\title{
杰出的贡献育人的典范
}

\section{- - 深切怀念施成熙教授--}

梁瑞驹

(河海大学)
王洪道

(中国科学院南京地理与湖泊甜究所)

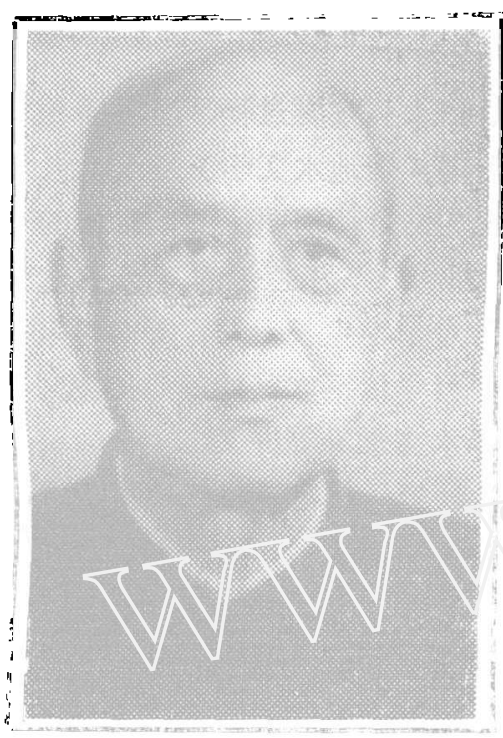

我国著名的科学家和漖育家、找国湖泊科学砳究的开拓 者、中国湖泊水文学的基人、河海大基教授施成熙先生因 积劳成疾医治无效，予1990年 1 月13日部开了我们，终年八

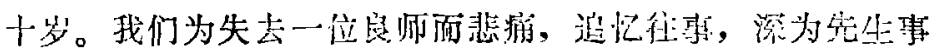
迹肪感动。在他度过的八十个春秋里，为祖国为人玨作出了

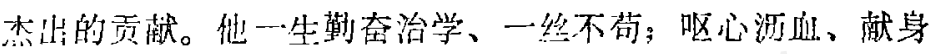

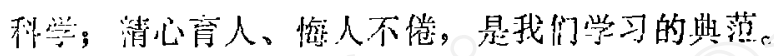

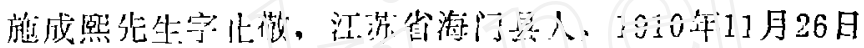

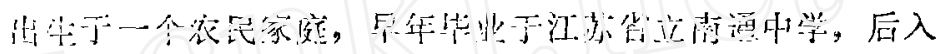

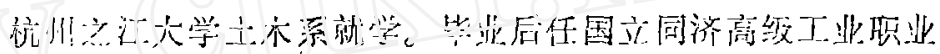

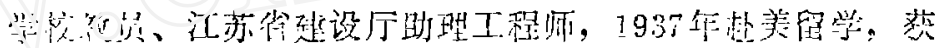

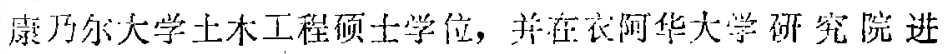

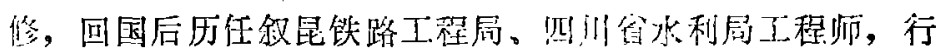
政院水利委员会技正、水利部讨察工程泎，台㜔省水利局顾 问菲总工程师，国立渐江大学上木系教授，复旦大学土木系教授兼主任，乡村教育学院水利 系教授, 之江大学土木系教授。解放后, 任华东军政委员会水利部水文资料整理委员会副主 任、主任、华东军政委员会水利部测验处副处长, 华东水利学院教授, 陆地水文教研组及海 洋水文教研组主任, 中国科学院兼任研究员, 南京地理所湖泊室主任, 国务院围湖围海小组 成员, 中国海洋湖沼学会副理事长, 江苏省海洋湖沼学会理事长, 中图坆理学会水女专业委 员会副主任等职。施成矢先生还坦任过河海大学工会主席、江沵省第三局科胁委员，江苏少 第三、四、五届政协委员。南京地理与湖泊所特约研究员和学术婪员。些外, 他还是《中国 大百科全书水文利学卷》缩委会主任, 地表水水文学组主编, 《中国虾业百科全书水利卷》

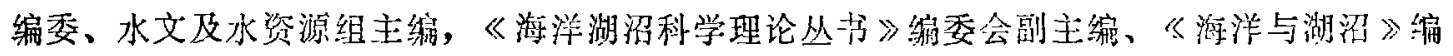

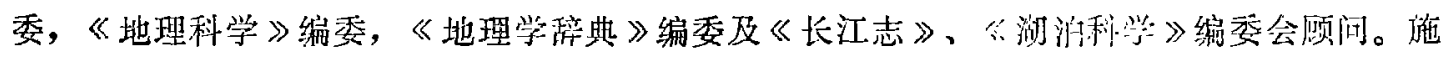
成熙先生晚年还担任江洂省海洋湖沼学会名誉理事长, 中国海洋湖沼兴会顾问。施成熙先生

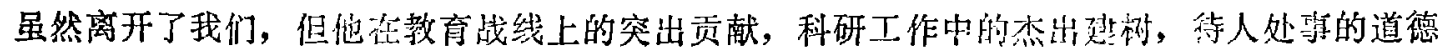
风范, 均堪称师表, 是我们学习的榜样。

\section{一、教育书人 潜心著述}

施成熙先生长期从事水利、水文和湖泊方面的教育和研究工作，有湖博的理论知识和丰 
富的实践经验、解放前, 先后讲授过 “河工学”、“水文学”、“灌溉工程”、“水力发 电、”、“海港工程”、“水工设计”等课程。解放后讲授 “陆地水文学”、“水利调查”、 “湖沼学” 等课程。在多年水文学的教学过程中, 他提出混和与平衡是水文学的主要基本理 论, 并据此讲授, 概念清楚, 效果良好。施先生注重理论联系实际, 多次组织青年教师和科 研人员及学生进行河流的水利调查, 湖泊的综合调查研究, 锻炼和培养了一支湖泊科学研究 的骨干力量。他平时对同学要求严格, 常勉励同学认真学习, 善于思考, 勇于实践; 细心观 察, 发现问题, 解决问题。他还主持建设了校内实验场地, 内设蒸发场与径流场, 校外实验 基地一一宜兴茗岭径流实验站, 供师生进行科研与实习。他先后赴长春地理研究所, 东北师 范大学及合肥工业大学讲学, 垪授沼泽水文学及冰情研究问题, 为开展中国沼泽研究及提高 冰情研究水平作出了贡献。

他的著作: 《台湾省之农田水利》, 详尽论述了台湾省农田水利发展过程, 灌溉面积及 其分布情况，是一部农田水利方面重要文献资料。解放后所著的《陆地水文学》及与他人合 编的《陆地水文学原理》两书, 将水文学理论与中国实际情况相结合, 烊明了不同水体的水 文现像与运动规律。根据他的水文学应为农业丰产服务的夙愿, 以他为主 编的《农业水文 学》, 阐述了水分一土壤一植物系统中与农业有关的水文条件对植物生长、发育等的影响, 是中国第一部农业水文专著, 为科学种田、合理用水, 提供了科学依据。此外，他远编写了 《水利调查》、《水文物理》、《湖泊水库水文学》及《沼泽水文学》等讲义。

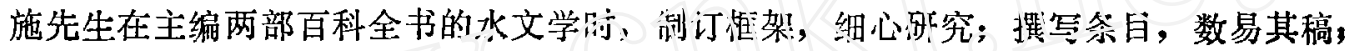

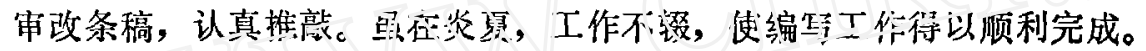

\section{二、呕心励血 献身科学}

施成熙先生早年撰写了航空摄影测量、土地整理、农田水利、港务管理等论文，分别发 表在当时的有关学报上。解放后, 他从事中国河流分类研究, 根据河流的水源与径流的年内 分配, 将中国河流分为三类十五型, 在全苏第三届水文会议上宣读, 并刊登在该次会议论文 集上。此后, 他对水面蒸发的观测、实验与计算 方法的研 究, 致力颇多。他建议改进 $\mathrm{E}_{801}$ 蒸发器的安装方法, 以提嵪观测精度; 指导玻璃钢蒸发器的研制, 以改善仪器性能; 提供图 纸、资料, 指导外单位建设蒸发实验站; 亲自进行抑制蒸发实验, 探索节水途径; 搜集全国 蒸发实验站资料, 制定蒸发器折算系数与符合中国实际情况的确定水面蒸发模型, 制成上海 经济区自然水面蒸发等值线图, 以便估算点发量。他先后发表这方面的论文多篇, 其中《确 定水面蒸发模型》更《水面蒸发器折算系数研究》二文, 获得水电部科学技术进步奖。

施成熙先生热心中国湖泊研究事业, 是我国湖泊学研究的开拓者。1958年受中国科学院 委托, 负责开展湖泊研究工作, 创建中国第一个湖泊综合研究机构一一南京地理研究所湖泊 室。该室内设水文气象、地质地貌、水化学、水生物四组, 后发展为今天的南京地理与湖泊 研究所。他首先邀请专家并亲自带领学生不辞劳苦, 先后去翻阳湖与太湖之滨勘测, 选定湖 泊实验站站址, 并建成宜兴湖泊实验站, 开展湖泊水量平衡研究工作, 同时进行洮湖试点调 查。1959年以湖泊室为主, 组织有关高等院校和生产部门对苏南湖泊进行了自然条件与自然 资源的综合调查。在调查过程中, 他发现温带浅水湖泊的多循环现象, 改变了传统的双循环 概念。此后陆续组织了巢湖、洪泽湖、鄱阳湖和华阳河流域湖群等调查研究。在此期间, 发表 
了与他同事和学生合作的《江劦南部湖泊综合调查研究》，《洪泽湖水文特征》，《鄱阳湖 水沙平衡初步分析》, 《巢湖水文特性》等文章, 分析了湖泊水文现象变化规律, 提出了湖 泊资源综合利用意见。“文革”之后, 发表了《太湖生态系统研究刍议》, 《湖泊闸坝水库 工程对环境影响评价》等文音。他还与湖泊室的有关同志一道, 先后主编出版了《江苏湖泊 志》和《中国湖泊概论》两部专著, 填补了中国湖泊学研究的一项空白。

1979年国家科委二局组织湖泊研究汇报会, 施先生以古稀之年受江苏地理研究所 ( 南京 地理与湖泊研究所) 的委托, 与该所两位中年同志去北京赴会, 向国家科委、中国科学院及 水利电力部等有关部门的领导同志汇报了国内湖泊科学研究现状、存在的问题及与世界先进 水平的差距, 受到领导的重视, 促进在 “文革” 中被下放 的江 苏地理 所重新回归中国科学 院。此后, 施成熙先生在中园地理学会广州会议和中国海洋湖沼学会武汉及青岛会议上, 多 次呼吁国家要重视湖泊科学研究, 建立专业科研机构。现在, 南京地理研究所已扩展为南京 地理与湖泊研究所。他的众多论文与专著, 对我国陆地水文学与湖泊学作出了杰出的贡献。 此外, 对年轻的冰雪与沼泽研究工作, 先生也关心扶持, 给予指导。

\section{三、知识洣博 平易近人}

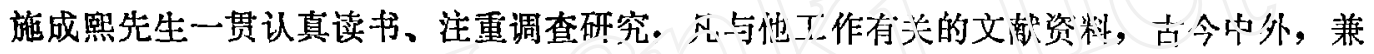

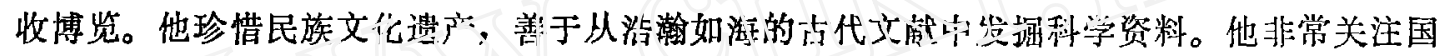

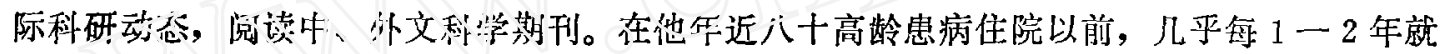
要撰写一笛花关水面蒸泣、湖泊学、水文学、环境与生态等方面的研究现状、研究方法和发 展趋势等内容的动态性文音。例如, 《湖泊水文科学研究现状与趋势》, 《湖泊科学研究三 十年与展望》等。这些文章有的发表在重要的学术期刊上, 有的在重要的学术会议上进行交 流，对从事这些方面研究工作的同志，有着重要的参考价值。

施成熙先生待人诚恩、和蔼谦逊、胸怀坦白、平易近人，凡与他有过接触的人都认为他 是一位关心他人，爱护同志和学生、奖掖后进，受人敬重的良师益友。他在主编《江苏湖泊 志》和 《中国湖泊概论》两书时, 正值炎热夏季, “火炉” 似的南京, 气温常高达 $36^{\circ} \mathrm{C}$ 以上, 先生克服酷暑, 始终一丝不荷, 认真地审阅书稿, 并提出具体修改的意见, 保证了出版的质 量。施先生桃李遍全国，凡已毕业的学生或晚辈请教问题或找他审阅 抢稿与评定论文稿件 时, 总是有求必应, 从不因故推托; 工作再忙都要挤出时间仔细审阅, 提出自己看法, 亲自 复信或约时面谈, 非常具体地加以指导。先生对晩拝或青年人总是循循善诱, 启发地提出问 题, 平等地进行讨论, 鼓励并尊重中、青年同志的正确意见。现在有不少中年同志在先生的 帮助和教育下，在教育、科研上均有一定的建树，成为教学与科研战线上的骨干力量。

\section{四、团结共事 甘为人梯}

1979年 2 月施成熙先生受中国海洋湖沼学会的委托, 筹建江苏省海洋湖沼学会。尽管他 已达七十高龄, 但极积性不减当年, 担负起繁重的筹建任 务, 与有关专家、教 授频繁地砟 商, 到有关部门争取支持。在他的努力下, 仅仅经过两个多月的筹备, 就正式成立了江苏省 省海洋湖沼学会。学会成立最初的 $1 \sim 2$ 年, 他亲自安排了海洋湖沼知识系列诽座, 在报刊 
上进行有关的科普宣传, 扩大学会的影响, 取得了明显的社会效果。施先生主持学会工作, 非常注意发挥学会横向联系的智力优势。近几年先后为江苏省政府和有关部门主持了“江苏 省大水面利用”、“苏南小湖群开发利用” 和 “苏北小湖群 利用” 等重 要的 咨询 活动。此 外，在省科协领导下，与其他学会对江苏省沿海滩涂资源及全省水资源利用等也进行了决策 盗询。在这些重大决策活动中，施成熙先生常常从计划抓起，动员学会内有关的专家学者参 加, 并注意发挥他们的积极性。在施老以身作则的精神影响下，学会各项咨询活动都进行得 卓有成效，获得省科协的好评。施成熙先生还非常重视发挥学会的学术团体的作用，坚持每 两年召开一次学术年会, 交流奋战在全省海洋湖沼各条战线上同志们的科研与工作成果, 为 发展江苏省海洋湖沼资源的优势出谋献策。他也非常珍惜会员们的优秀成果，年会以后就抓 紧安排论文集的选稿、编辑和出版工作。学会经费紧，他尽量压缩学会开支，支持论文集的 出版，有时还亲自出面筹集资金。在他的关心和支持下，论文集已出版了三集，每集论文都 凝结了先生辛勤的劳动。最难能可贵的是, 他于1987年年底曾患病住院, 还非常关心学会的 活动, 了解一些重要咨询活动进展的情况, 并提出自己的意见, 参加咨询活动的同志们都非 常感动。

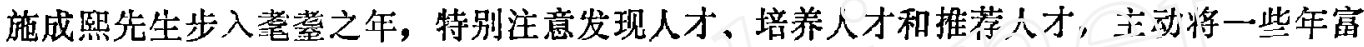
力强的同志推葆到全国学会理事会的岗位上去。近几年，他体弱多淓，曾结次问省㳆协和学 会理事会表示要从学会领导岩位上退下来, 将那些善于固结人，组织能力强又有学术水平的

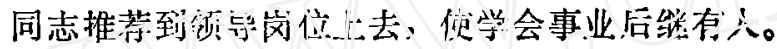

\section{五、克勤克俭 高风亮节}

施成熙先生在生活上非常俭朴, 对自己要求十分严格。家中除书柜书架等摆设外, 几乎 没有什么现代化的家俱, 客厅里唯一的一张长沙发, 也几经整修, 一直沿用至今; 他平日衣 着朴素，几套出客衣服还是50年代添制的; 他饮食也不讲究，更没有烟酒等噌好。可是他对 社会福利等事业却给予了最大的关怀。50年代后期和 60 年代初期, 他在南京地理所兼职时, 叫人将他的兼职费存入银行, 1962年苏北发生灾荒, 施先生毫不犹豫地将 1 千多元兼 职费 全部捐献给苏北救灾。文革后，他又将文革中被非法抄家的退赔款全部捐增给中国儿童福利 基金会。最使我们感动的是他在重病期间还关心教学和科研工作，如审阅稿件，回答来访者 提出的问题等等，在他病危弥留之际，还处处为学校着想，表现了先生的崇高品质。他留下 遗言, 感谢学校领导对他的深情厚谊, 务请学校节约人力财力, 从简办理他的丧事, 并教育 子女柇持自重, 不要向学校提出份外的要求。

施成熙先生和我们永别了, 但他的高风亮节将永远激励和教育我们活着的人, 我们要化 悲痛为力量, 努力工作, 完成先生未竟的事业。

\section{OUTSTANDING CONTRIBUTION, EDUCATIONAL MODEL}

\section{-DEEPLY CHERISH THE MEMORY OF PROFESSOR SHI CHENGXI}

Liang Ruiju

(Hehai University)
Wang Hongdao 